\title{
El contexto de Melilla
}

Juan Francisco Mayoral del Amo

Educador Social

\section{El contexto de Melilla}

\subsection{Descripción Geográfica (1)}

La ciudad de Melilla se encuentra situada en el Norte de África, enclavada en territorio del Reino de Marruecos, entre el cabo Tres Forcas y el cabo de Água. Se encuentra a una distancia de 114 millas naúticas de Málaga y de 97 de Almería y a una distancia de Ceuta de aproximadamente $380 \mathrm{~km}$ por carretera. Limita con el mar Mediterráneo y la provincia de Nador, cábila de Mazuza.

Su superficie es de $12,33 \mathrm{~km}^{2}$, tiene forma ahusada y su perímetro tiene aproximadamente $17 \mathrm{~km}$. Todo el perímetro fronterizo con Marruecos se encuentra rodeado de una doble valla con puestos de vigilancia y control. Existen cuatro puestos fronterizos, de los cuales dos permiten el tránsito de vehículos (Beni Enzar y Farhana) y los otros dos son peatonales (Barrio Chino y Mariguari). Se distingue una pequeña península, donde se encuentra enclavada la ciudadela amurallada de Melilla la Vieja (el primer enclave de la ciudad), Al sur de esta se encuentra una llanura que limita con el litiral. Hacia el norte y oeste la superficie es bastante accidentada, con cinco cerros cuya máxima altura es de $130 \mathrm{~m}$. (en el cerro de Rostrogordo) y los acantilados de Horcas, Rostrogordo y Aguadú.

La atraviesa el río Oro y el arroyo Mezquita, ambos secos habitualmente, con caudal sólo en epocas de lluvia.

Su clima es Mediterraneo, con escasas precipitaciones. Se alternan los vientos de Poniente y Levante.

Administrativamente se divide en ocho distritos, a su vez divididos en secciones que no corresponden a barrios completos sino a conjuntos de calles. 


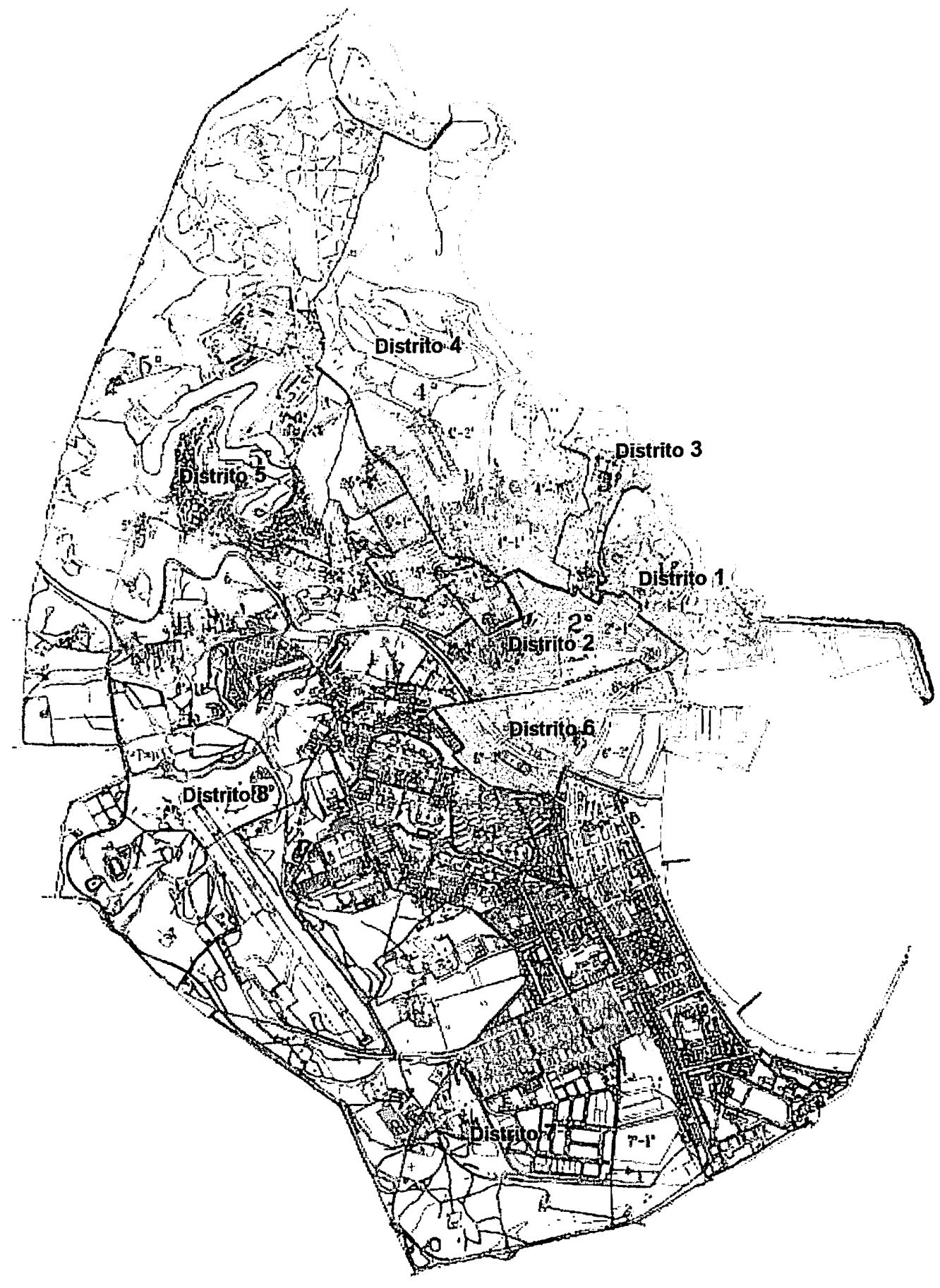




\section{2. Descripción demográfica}

La población de Melilla, según el padrón de 2000, es de 69.983 habitantes, aunque es difícil calcular la población real, dado que en Melilla reside gran número de personas sin documentación y de que existe una numerosa población flotante que cruza la frontera cada día para trabajar o comerciar en Melilla. La distribución de la población por distritos es muy desigual, como se muestra en el cuadro 1.

\begin{tabular}{lcc} 
Cuadra 1: Distribución de la población por distritos \\
\cline { 2 - 3 } & Habitantes & Porcentaja \\
\hline Distrito 1 & 2679 & $3,8 \%$ \\
Distrito 2 & 5974 & $8,5 \%$ \\
Distrito 3 & 2394 & $3,4 \%$ \\
Distrito 4 & 7318 & $10,5 \%$ \\
Distrito 5 & 13619 & $19,5 \%$ \\
Distrito 6 & 4435 & $6,3 \%$ \\
Distrito 7 & 7299 & $10,49 \%$ \\
Distrito 8 & 26265 & $37,5 \%$ \\
Total & 69983 & $100,09 \%$
\end{tabular}

Gráfico 2: Distribución de la población por distritos

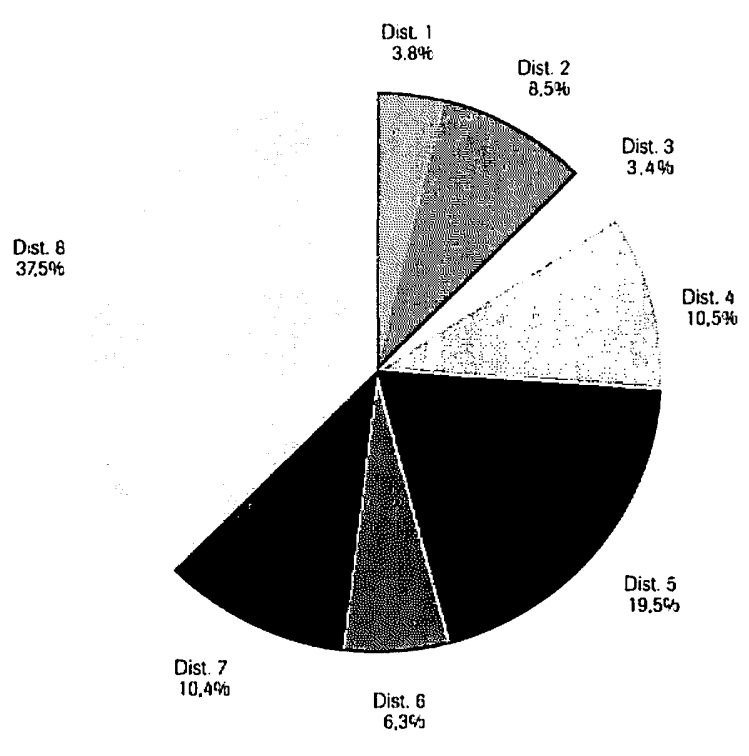

Fuente: Elaboración propa sobre actualización del pacrón de 2000

El $90,7 \%$ de la población ( 63.500 personas) es de nacionalidad española. El 8,8,\% (6.124 personas) de nacionalidad marroquí, y el $0,5 \%$ restante se reparte entre diversas nacionalidades. 
La densidad de población en la ciudad de Melilla es de 5.677 habitantes por km². Su tasa de natalidad en 1999 es $1.68 \%$, frente al $0.98 \%$ de España, y el índice de mortalidad en el mismo año de un $0,62 \%(0,94 \%$ es la media española). Esto nos da un crecimiento vegetativo de 1,06 por cien habitantes, frente al $0,04 \%$ de media española en el mismo año.

Cuadro 2: Evolución en la tasa de crecimiento vegetativo en Melilla (por cien habitantes)

\begin{tabular}{llllllllllllll}
\hline Año & 1987 & 1988 & 1989 & 1990 & 1991 & 1992 & 1993 & 1994 & 1995 & 1996 & 1997 & 1998 & 1999 \\
\hline Crec. & 1.14 & 1.06 & 1,12 & 1.19 & 1,16 & 1,45 & 1.20 & 1.05 & 0.92 & 1,17 & 1.07 & 0.95 & 1.06
\end{tabular}

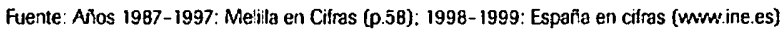

Como corresponde a la tasa de crecimiento, la población es joven, con una media de edad de 34,4 años (la desviación típica es de 21.12). cuadro 3 y gráficos 4,5 y 6). La pirámide de población muestra la configuración típica de una población joven y en crecimiento.

El número medio de personas por familia es de 4,32; con diferencia entre las familias de origen hispano y las de origen bereber. En las familias hispanas, el número medio de personas por familia es de 3,81, mientras que en las bereberes es 5,05 y en las mixtas (uno de los cónyuges de arigen hispano y el otro de origen rifeño), es de 4,25.

Cuadro 3: Distribución de la población por intervalos de edad y sexo

\begin{tabular}{|c|c|c|c|c|c|c|c|c|c|}
\hline & & Censo 19 & & & adrón 19 & & & Padrón 20 & \\
\hline & H & $M$ & TOTAL. & H & $M$ & TOTAL & H & $M$ & TOTAL \\
\hline 0 a 4 & 2337 & 2178 & 4515 & 2550 & 2314 & 4864 & 1864 & 1769 & 3633 \\
\hline 5 a 9 & 2654 & 2316 & 4970 & 2317 & 2269 & 4586 & 2559 & 2353 & 4912 \\
\hline 10 a 14 & 2648 & 2421 & 5069 & 2538 & 2410 & 4949 & 2819 & 2555 & 5374 \\
\hline 15 a 19 & 2431 & 2448 & 4879 & 2650 & 2606 & 5257 & 3558 & 3047 & 6605 \\
\hline 20 a 24 & 2587 & 2529 & 5116 & 2619 & 2556 & 5175 & 3232 & 2942 & 6174 \\
\hline 25 a 29 & 2685 & 2585 & 5270 & 2798 & 2643 & 5441 & 3214 & 2960 & 6174 \\
\hline 30 a 34 & 2486 & 2393 & 4879 & 2699 & 2525 & 5224 & 3043 & 2918 & 5961 \\
\hline 35 a 39 & 1888 & 1745 & 3633 & 2523 & 2318 & 4842 & 2937 & 2605 & 5542 \\
\hline 40 a 44 & 1352 & 1390 & 2742 & 1923 & 1735 & 3658 & 2255 & 1958 & 4213 \\
\hline 45 a 49 & 1221 & 1321 & 2542 & 1364 & 1309 & 2674 & 2843 & 2452 & 5295 \\
\hline 50 a 54 & 1192 & 1341 & 2533 & 1235 & 1271 & 2506 & 1607 & 1438 & 3045 \\
\hline 55 a 59 & 1177 & 1410 & 2587 & 1108 & 1259 & 2317 & 1379 & 1377 & 2756 \\
\hline 60 a 64 & 1132 & 1360 & 2492 & 1063 & 1319 & 2381 & 1185 & $123 B$ & 2423 \\
\hline 65 a 69 & 949 & 1158 & 2107 & 890 & 1186 & 2076 & 1112 & 1389 & 2501 \\
\hline 70 a 74 & 584 & 795 & 1379 & 703 & 990 & 1693 & 898 & 1165 & 2063 \\
\hline 75 a 79 & 377 & 607 & 984 & 391 & 602 & 993 & 663 & 977 & 1640 \\
\hline 80 a 84 & 175 & 411 & 586 & 176 & 372 & 548 & 353 & 576 & 929 \\
\hline 85 y más & 78 & 239 & 317 & 99 & 244 & 343 & 226 & 517 & 743 \\
\hline Total & 27953 & 28647 & 56600 & 29647 & 29929 & 59576 & 35747 & 34236 & 69983 \\
\hline
\end{tabular}


Gráfico 4: Pirámide de población censo de 1991

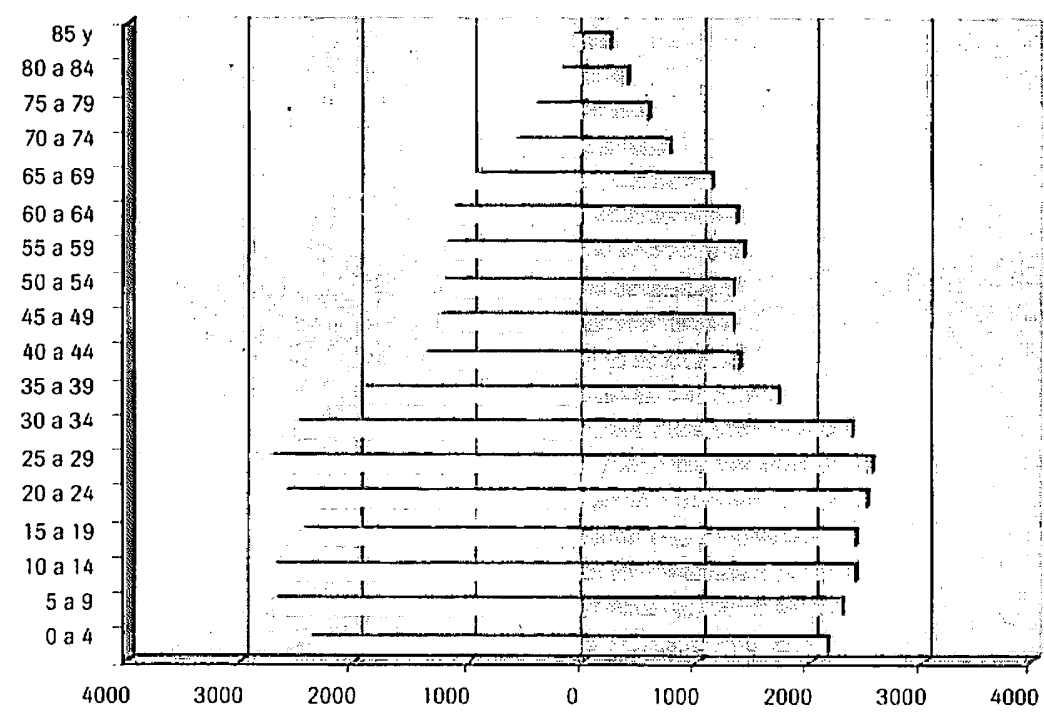

$\square$ Hombres

Mujeres

Grálico 5: Pirámide de población padrón de 1996

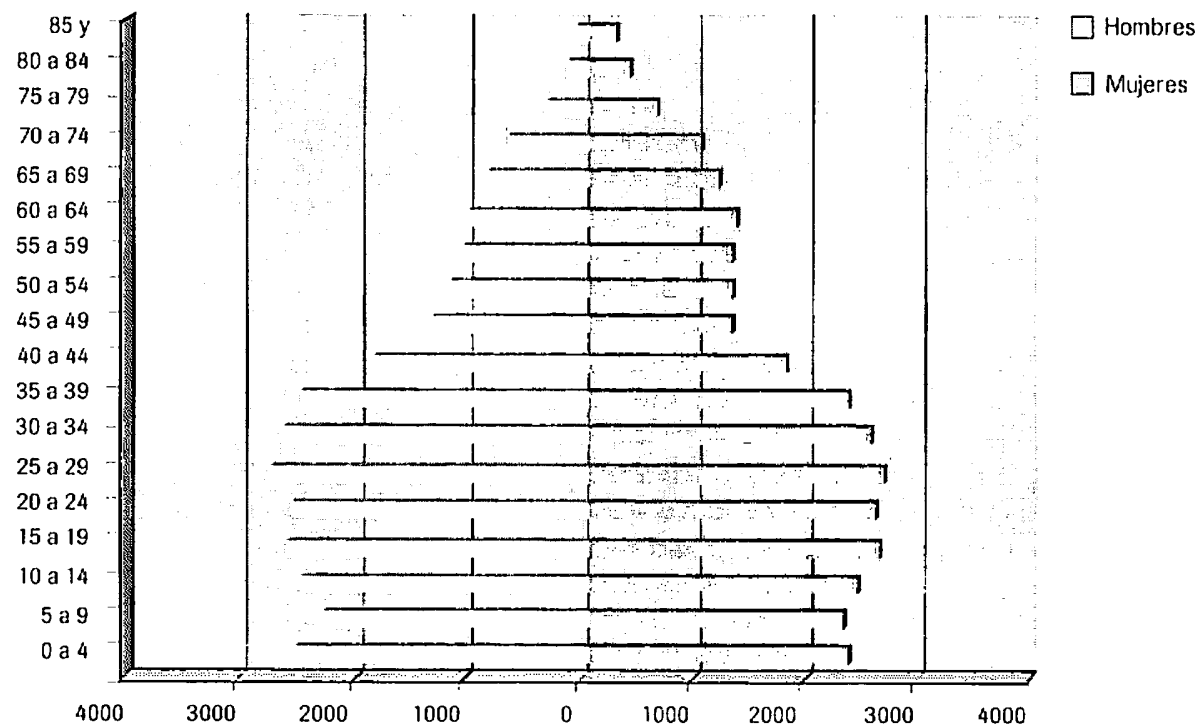


Gráfico 6: Pirámide de población padrón de 2000

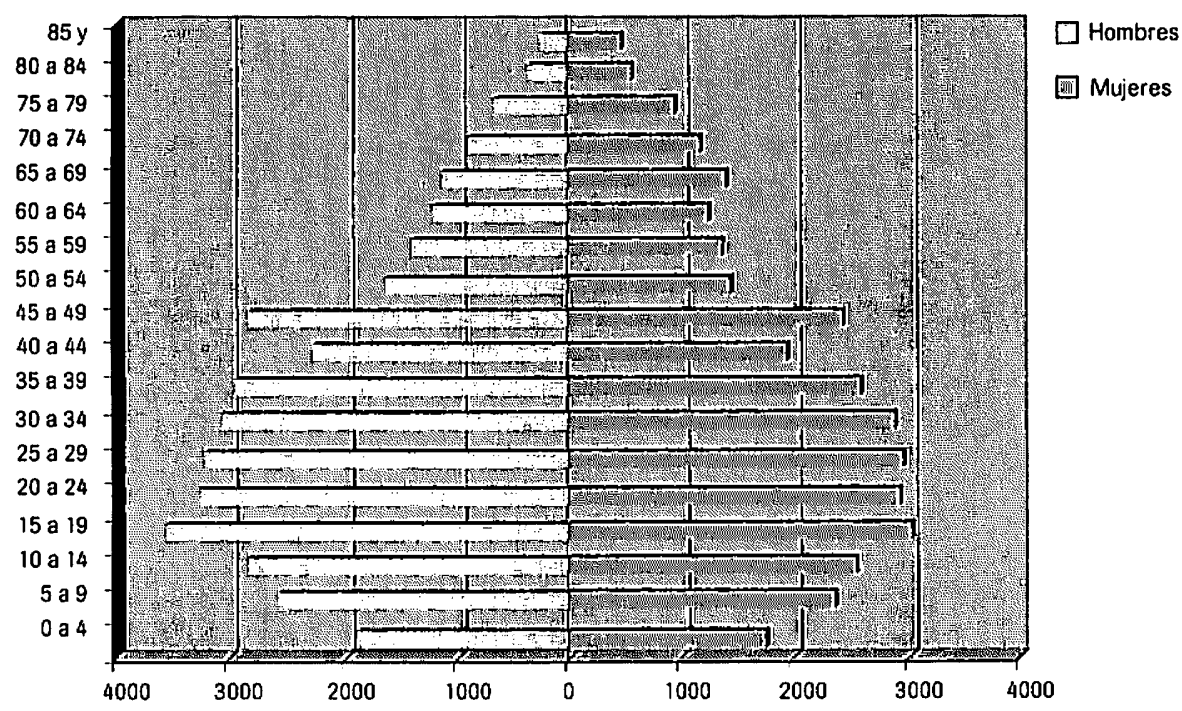

Por distritos, la media de edad es significativamente más baja en los distritos cuarto y quinto, ambos de población mayoritariamente bereber (cuadro 4).

\begin{tabular}{lccc}
\multicolumn{4}{l}{ Cuadro 4: Media de edad por distritos } \\
\hline Distrito & Media & N & Desv. tip. \\
1 & 36.27 & 2679 & 21.32 \\
2 & 39.15 & 5974 & 22.09 \\
3 & 37.49 & 2394 & 22.85 \\
4 & 31.76 & 7318 & 21.04 \\
5 & 30.78 & 13619 & 20.69 \\
6 & 37.61 & 4435 & 22.18 \\
7 & 34,61 & 7299 & 21.13 \\
8 & 34.83 & 26265 & 20,34 \\
Total & 34.39 & 69983 & 21.11 \\
\hline
\end{tabular}

\subsection{Descripción socio-cultural}

Su situación geográfica y antecedentes históricos le dan a Melilla unos rasgos culturales peculiares, entre los que destacan la coexistencia de colectivos marcadamente diferenciados en cuanto a lengua, tradiciones, cultura y religión. Los dos colectivos mayoritarios son el de origen hispano, tradicionalmente identificado con las costumbres españolas y la religión católica, y el de origen rifeño o bereber, de lengua Tamazight y religión islámica. Existen también otros colectivos minoritarios, pero con una activa presencia en la vida 
social y en la economía melillense: el hebreo (alrededor de un $1 \%$ de la población), el hindú (aproximadamente sesenta personas) y el Romani (unas doscientas personas).

Cuadro 5: Distribución de familias por culturas

\begin{tabular}{lcc}
\hline & Porcentaje & Porcentaje acumulado \\
\hline Hispana & $52.8 \%$ & $52.8 \%$ \\
Hebrea & $1,0 \%$ & $53,8 \%$ \\
Bereber & $38,2 \%$ & $92.0 \%$ \\
Mixta (hispano-bereber) & $8,0 \%$ & $100.0 \%$ \\
Total & $100,0 \%$ & \\
\hline
\end{tabular}

Fuente: elaboración propia sobre datos de la encuesta realizada por el Pacto Territorial par el Empleo (2).

Grafico 7: Porcentaje de familias por culturas

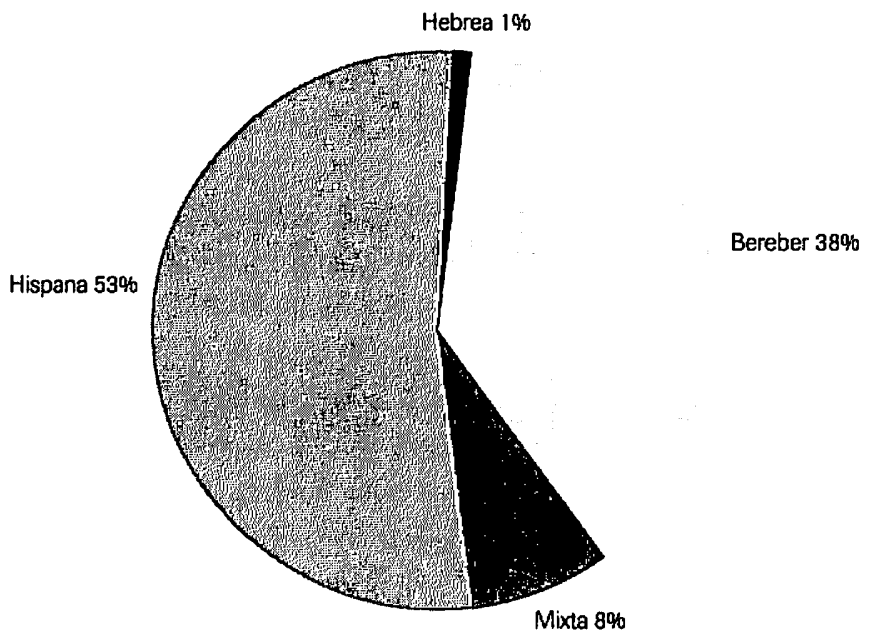

2. Estos datos. y los que en lo sucesivo refieran como fuente la encuesta realizada por el Pacto Territorial por el Empleo, tiene como referencia un cuestionario sobre cuestiones sociales y económicas, que forma parte del Estudio Social que realizan los técnicos del Pacto Territorial por el Empleo, aún no publicado, y en el que el autor de este trabajo está participando. Este cuestionario se compone de 50 items. El universo de la encuesta es las unidades familiares de la ciudad de Melilla entendiendo como tales los hogares en los que convivan dos o más personas con lazos de parentesco. La muestra teórica es de 200 unidades, distribuidas en ocho zonas, correspondientes a los distritos administrativos de Melilla, con una distribución comespondiente al peso de la población de cada distrito. Esta muestra se seleccionó de forma aleatoria sobre el padrón municipal, seleccionándose tres sustituciones para cada encuesta. en el caso de no estar habitado el domicilio seleccionado. de no reunir las condiciones requeridas o de negarse a responder a la encuesta Se recoge así información directa sobre 199 familias (una de las encuestas fue desestimada por no presentar las características de fiabilidad requeridas) y 859 personas, de las cuales 605 son mayores de 16 años. El trabajo de campo se lievó a cabo durante el mes de noviembre de 2000 por un equipo de diez entrevistadores del equipo del Area Social del Pacto Territorial por el Empleo. El proceso de datos siguió el proceso de depuración de inconsistencias y revisión de las encuestas. rechazando las inconsistentes. grabación de datos y corrección de los errores de grabación, aplicación de los coeficientes de ocultación en los datos económicos directos y elaboración de las tablas de frecuencias. medias estadisticas y correlaciones bivariables con indicadores estadísticos, usando el programa informático SPS. 
El distrito uno corresponde a la ciudadela del casco antiguo de Melilla, conocida como "El Pueblo" o "Melilla la Vieja". En ella se encuentra un conjunto de edificaciones históricas, reconvertidas en museos o en instalaciones de uso público. Las casas de esta zona son de dos tipos: casamatas en las que viven familias arraigadas en este barrio y bloques de pisos de protección oficial de reciente construcción.

Los distritos dos y seis, constituyen el centro de la ciudad. Es la zona de mayor actividad comercial, en la que se encuentran la mayoría de las entidades bancarias y dependencias administrativas.

El distrito tres es también zona céntrica y de actividad comercial, pero con características propias de la población bereber, mayoritaria en ella. Existe multitud de comercios, almacenes y puestos de vendedores en la zona conocida como "el Polígono" y la calle Margallo y sus aledaños.

Algunos sectores de los distritos tercero, cuarto y quinto están compuestos casi exclusivamente por población de origen bereber (monte de María Cristina, Barrio Hebreo, Polígono de la Paz, Cañada de Hidum, Barrio de los Cuernos). En la Cañada de Hidum, también conocida como "Cañada de la Muerte", la forma de vida se ajusta a los patrones de la cultura rifeña en cuanto a lengua costumbres, forma de las construcciones y organización social. La mayoría de las edificaciones son asentamientos ilegales, por no tener los habitantes la propiedad del terreno y haberse realizado las casas al margen de toda normativa o control oficial. Este barrio es muy poco frecuentado por personas procedentes de otras zonas de la ciudad, manteniendo un fuerte carácter de gueto. Otros barrios con predominio de población bereber (Monte de María Cristina. Polígono de la Paz) están algo más integrados dentro del conjunto de la ciudad.

El distrito siete, o barrio del Real es un barrio compuesto fundamentalmente por casamatas (aunque se están construyendo muchos bloques de pisos], de trazado lineal, habitado principalmente por familias de clase media. En él se encuentra el polígono del SEPES, zona de naves dedicadas principalmente al almacenaje y la venta al por mayor. Hasta el mes de julio de 2001 existía en este distrito una zona de viviendas prefabricadas conocida como "Las Caracolas", que era un gueto con población casi exclusivamente de origen bereber y de muy escasos recursos económicos. Los pobladores de esta barriada han sido trasladados recientemente a la "Urbanización las Palmeras", situada en el distrito quinto, cerca de la Cañada de Hidum, aumentando así la concentración de población de escasos recursos y potencialmente conflictiva en esta zona.

El distrito ocho es el más grande, poblado y heterogéneo. En este distrito hay una gran diversidad social. Tiene zonas de pisos de lujo Paseo Marítimo, urbanizaciones de "chales" (Mayorazgo) y quintas (carretera de Farhana), bloques de viviendas sociales (Minas del Rif, Barriada de la Constitución), viviendas militares (zona de Alfonso XIII). bloques "colmena" (Viviendas Rusadir, Urb. Ciudad de Málaga) y barrios de casamatas de gran arraigo en la ciudad (barrio de la Libertad, barrio de la Victoria). También se encuentra en este distrito la frontera de Beni-Enzar, lugar de gran tráfico de personas y actividad comercial con Marruecos. 
Cuadro 6: Distribución de culturas por distritos

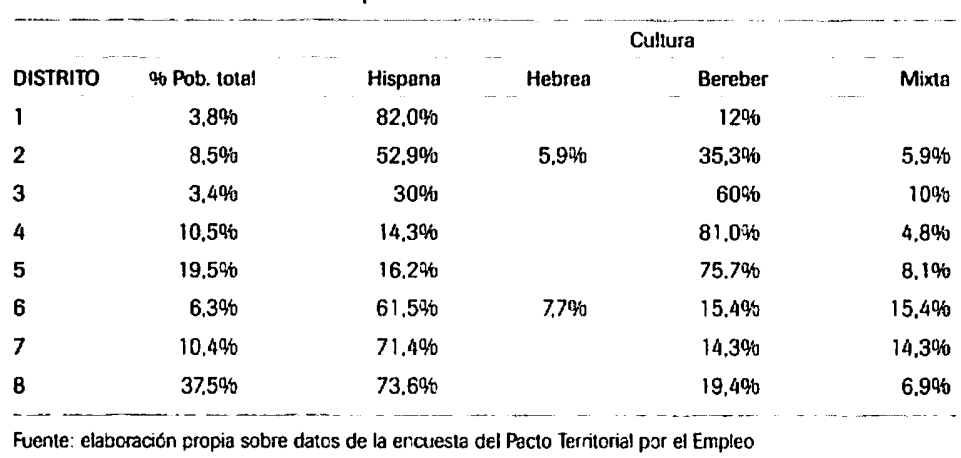

El nivel educativo medio de Melilla se puede considerar bajo. El porcentaje de analfabetismo absoluto es de un 15\%, con especial incidencia en las personas de cultura bereber $y$, concretamente en las mujeres de este grupo cultural. En cambio en los niveles superiores se acortan las diferencias formativas entre hombres y mujeres, dándose parecidos porcentajes de bachilleres y universitarios.

En el colectivo de las familias de origen hispano y en las mixtas hispano-bereber, se da también una notable diferencia formativa entre hombres y mujeres.

Por distritos, son el quinto, tercero y cuarto los de menor nivel educativo, coincidiendo con aquellos en la que la población de origen rifeño es mayoritaria.

Cuadro 7: Nivel de estudios por cultura y género (mayores 16 años) (3)

\begin{tabular}{|c|c|c|c|c|c|c|c|c|}
\hline & \multicolumn{2}{|c|}{ Hispana } & \multicolumn{2}{|c|}{ Bereber } & \multicolumn{2}{|c|}{ Mixta } & \multicolumn{2}{|c|}{ Total } \\
\hline & H & M & H & $M$ & H & $M$ & H & $M$ \\
\hline No sabe leer & 1,390 & $6,5 \%$ & $8,5 \%$ & 28,696 & 4,290 & $5,0 \%$ & $\quad 4,396$ & $15.5 \%$ \\
\hline Menos de 6 años de escuela & $9.0 \%$ & $14.9 \%$ & $26,5^{\circ} \%$ & $19.8 \%$ & $12.5 \%$ & $20,0 \%$ & 16.190 & 17,180 \\
\hline Estudios primarios completos & 17.390 & 24.096 & 25,690 & 21.496 & $33.3 \%$ & $25,0 \%$ & $22,1 \%$ & 22,790 \\
\hline F. P. 1er grado & 9.690 & $4.5 \%$ & 9.496 & $1.69 \%$ & $8.3 \%$ & 5.096 & 9.496 & 3.396 \\
\hline F. P. $2^{\circ}$ grado & $4.5 \%$ & 2.690 & 5.190 & 1.695 & $8,3 \%$ & & $5,0 \%$ & 2.096 \\
\hline Bachiller elemental & $12,2 \%$ & $11,0 \%$ & 8.596 & $15,1 \%$ & $12,5 \%$ & 15.096 & $10.7 \%$ & $12.8 \%$ \\
\hline Bachiller superior & $26.3 \%$ & $16,2 \%$ & $10.3 \%$ & $9,5 \%$ & $8.3 \%$ & 25.098 & 18.740 & $14.8 \%$ \\
\hline Universitarios grado medio & $10,3 \%$ & $14,99 \%$ & 2.690 & $1,6 \%$ & 4.296 & & $6.7 \%$ & $8.69 \%$ \\
\hline Universitarios grado superior & $8.3 \%$ & $2,6 \%$ & $1.7 \%$ & $.8 \%$ & 8.390 & $5.0 \%$ & 5.798 & $2.0 \%$ \\
\hline Doctorado o postgrado & .696 & 1.990 & & & & & 0.396 & 1,040 \\
\hline Otros estudios & $.69 \%$ & & & & & & $0.3 \%$ & \\
\hline NS/NC & & 0.695 & 1,790 & & & & $4.3 \%$ & \\
\hline
\end{tabular}

Fuente: elaboración propia sobre datos de la encuesta del Pacto Terrilorial Por el Empleo 
Cuadro B: Nivel de estudios por distritos (mayores 16 años)

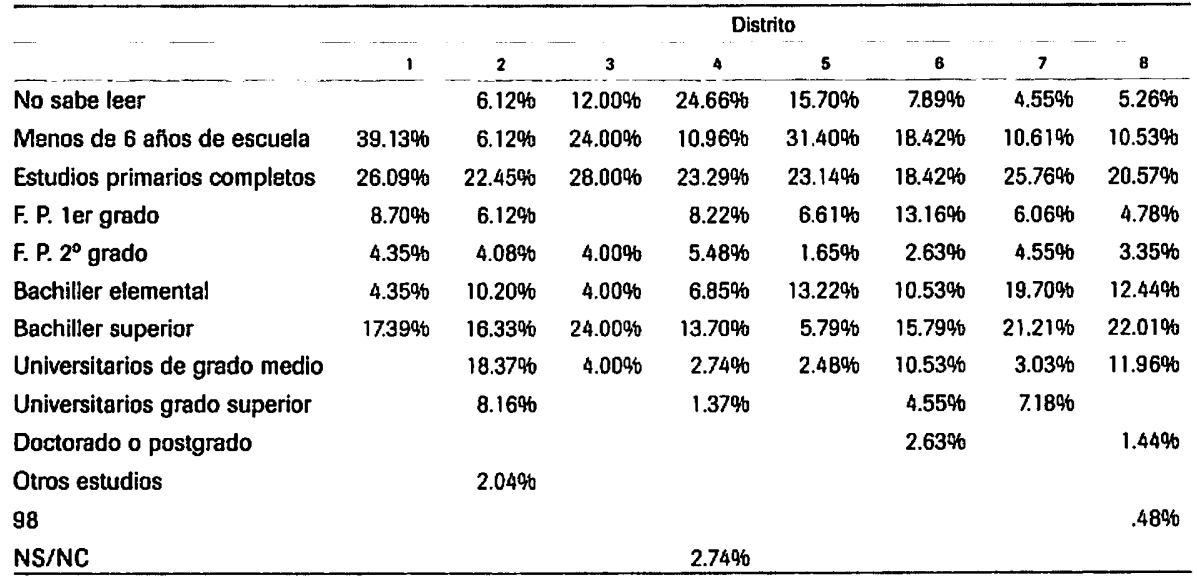

Fuente: ełaboración propia sobre datos de la encuesta realizada por el Pacto Territorial por el Empleo

El desempleo es uno de los mayores problemas de Melilla. Con una tasa de paro superior en más de tres puntos a la media nacional, y en la que no se aprecia un descenso significativo desde 1997. Las medidas gubernativas de lucha contra el desempleo, fundamentalmente basadas en planes de empleo semestrales, no parece que den frutos en una disminución del paro estructural. Existe mucho empleo no registrado, con el trabajo de marroquíes que cruzan la frontera cada día o que residen en Melilla de forma irregular. En el servicio doméstico es una práctica bastante normal no regularizar los contratos ni dar de alta en la seguridad social a las trabajadoras transfronterizas o residentes ilegales en Melilla. También es habitual encontrar naves o locales que permanecen cerrados por fuera, incluso con candados, y sin embargo se escucha dentro el ruido de máquinas y de personas trabajando.

Cuadro 9: Evolución de la tasa de desempleo en Melilla

\begin{tabular}{lcccccc}
\hline & 1996 & 1997 & 1998 & 1999 & 2000 & 2001 \\
\hline Enero & 17,71 & 15,39 & 16,49 & 14.77 & 13.98 & 15.74 \\
Febrero & 18,05 & 15,90 & 16,74 & 14.58 & 14.56 & 15.84 \\
Marzo & 18.64 & 16,06 & 16,81 & 14.91 & 14.70 & 16,26 \\
Abril & 18.29 & 15.20 & 15,83 & 14.60 & 14.98 & 15.95 \\
Mayo & 17.50 & 14.52 & 15.65 & 13.94 & 14.95 & 15.68 \\
Junio & 17,05 & 14,57 & 15,10 & 14.33 & 14.27 & 14,85 \\
Julio & 14,52 & 13,79 & 14,57 & 13.50 & 13.74 & 13,43 \\
Agosto & 13,90 & 12.96 & 13.83 & 13.42 & 13.45 & \\
Septiembre & 14.20 & 13.74 & 14.59 & 13.51 & 13.72 & \\
Octubre & 14.70 & 14,48 & 14,49 & 13.91 & 14.71 & \\
Noviembre & 15.29 & 14,89 & 14,61 & 14.35 & 14.92 & \\
Diciembre & 14,88 & 15,72 & 14,94 & 14.17 & 14.59 & \\
Media anual & 16.23 & 14.78 & 15,30 & 14,17 & 14.38 & \\
Media nacional & 14.28 & 13.15 & 11.60 & 10.06 & 11.60 & \\
\hline
\end{tabular}

Fuente: elaboración propia sobre datos del INEM (mww.inem.es) 
Gráfico 8: Comparativa en la evolución de la tasa de desempleo en Melilla y España

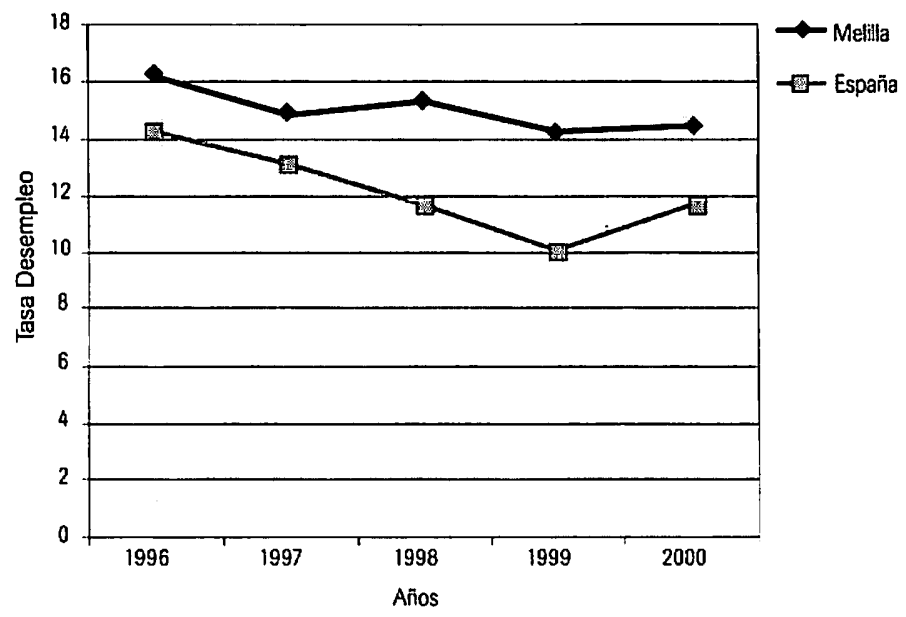

Por edades, el desempleo en Melilla tiene una incidencia más alta que la media nacional en los menores de veinticinco años, siendo, en cambio, más baja en el tramo de cincuenta a sesenta y cinco años.

Cuadro 10: Distribución del desempleo por edades en Melilla y España

\begin{tabular}{|c|c|c|c|c|c|c|c|c|c|c|c|}
\hline & TOTAL & $\begin{array}{l}<20 \\
\text { ANNOS }\end{array}$ & $\begin{array}{l}20-24 \\
\text { ANNOS }\end{array}$ & $\begin{array}{l}25-29 \\
\text { AÑOS }\end{array}$ & $\begin{array}{l}30-34 \\
\text { ANIOS }\end{array}$ & $\begin{array}{l}35-39 \\
\text { ANNOS }\end{array}$ & $\begin{array}{l}40-44 \\
\text { ANOS }\end{array}$ & $\begin{array}{l}45-49 \\
\text { AÑOS }\end{array}$ & $\begin{array}{l}50-54 \\
\text { ANNOS }\end{array}$ & $\begin{array}{l}55-59 \\
\text { AÑOS }\end{array}$ & $\begin{array}{l}60-65 \\
\text { ANOS }\end{array}$ \\
\hline MELILLA & 3.743 & 329 & 564 & 520 & 511 & 546 & 548 & 331 & 198 & 120 & 76 \\
\hline$\%$ & 10096 & 8.7945 & $15.07 \%$ & $13.89 \%$ & $13.65 \%$ & 14.5996 & 14.649 & 8.8496 & $5.29 \%$ & $3.21 \%$ & 2.0390 \\
\hline ESPAÑA & 1.460 .586 & 71.523 & 169.318 & 228.340 & 216.624 & 190.498 & 158.166 & 122.071 & 118.935 & 121.866 & 63.245 \\
\hline \% & $100 \%$ & $4.90 \%$ & $11.59 \%$ & 15.6390 & 14.8390 & 13.0496 & $10.83 \%$ & $8.36 \%$ & $8.14 \%$ & $8.34 \%$ & 4.3490 \\
\hline
\end{tabular}

Fuente: Elabaración propia sobre datos del INEM correspondientes a Junio de 2001 (unww.inem.es)

La duración de los periodos de desempleo tiende a agruparse en los extremos, siendo los desempleados con menos de seis meses el $43,39 \%$, y los parados de larga duración, con más de dos años desempleados, el 23,88\% (cuadros 11,12 y 13).

Cuadro 11: Distribución del desempleo por duración (meses) en Melilla y España

\begin{tabular}{lrrrrrrrrrr}
\hline TOTAL & $<=3$ & $>3<\mathrm{m}$ & $>6<\mathrm{m} 9$ & $>9<=12$ & $>12<=15$ & $>15<=18$ & $>18<21$ & $>21<=24$ & $>24$ \\
MELILLA & 3.743 & 1.000 & 624 & 354 & 296 & 171 & 172 & 98 & 134 & 894 \\
PORCENTAJE & $100 \%$ & $26.72 \%$ & $16.67 \%$ & $9.46 \%$ & $7.91 \%$ & $4.57 \%$ & $4.60 \%$ & $2.629 \%$ & $3.58 \%$ & $23.88 \%$ \\
ESPAÑA & 1.460 .586 & 502.886 & 228.591 & 142.254 & 99.342 & 62.871 & 58.406 & 48.603 & 38.258 & 279.375 \\
PORCENTAJE & $100 \%$ & $34.43 \%$ & $15.65 \%$ & $9.74 \%$ & $6.80 \%$ & $4.30 \%$ & $4.00 \%$ & $3.33 \%$ & $2.62 \%$ & $19.13 \%$ \\
\hline
\end{tabular}

Fuente: Elaboración propia sobre datos del INEM correspondientes a Junia de 2001 (umw.inem.es) 
Cuadro 12: Distribución del desempleo masculino por duración (meses) en Melilla y España

\begin{tabular}{|c|c|c|c|c|c|c|c|c|c|c|}
\hline & TOTAL & $<=3$ & 6 & $0<0$ & $>0<=12$ & $>12<15$ & $>15<=18$ & $>18<21$ & $>21<-24$ & $>24$ \\
\hline MELILLA & 1.176 & 491 & 240 & 102 & 74 & 51 & 45 & 18 & 28 & 127 \\
\hline$\%$ & $100 \%$ & $41.75 \%$ & 0.4195 & $8.67 \%$ & 6.2940 & 4.3496 & $3.83 \%$ & 1.5390 & $2.38 \%$ & 10.8095 \\
\hline $09{ }^{2}$ & 35.1 & 221.582 & 92.922 & 56.161 & 34.352 & 23.360 & 21.434 & 170 & 12.602 & 84.767 \\
\hline+0 & $100 \%$ & $39.21 \%$ & 16.4496 & $9.94 \%$ & 6.0896 & $4.13 \%$ & $3.79 \%$ & 3.1746 & 2.2396 & $15 \%$ \\
\hline
\end{tabular}

Fuente: Elabcración propia sobre datos del INEM correspondientes a Junio de 2001 (www.nem.es)

Cuadro 13: Distribución del desempleo femenino por duración (meses) en Melilla y España

\begin{tabular}{|c|c|c|c|c|c|c|c|c|c|c|}
\hline & TOTAL & $\Leftrightarrow 3$ & $>3<=6$ & $>6<=9$ & $>9<=12$ & $>12<=15$ & $>15<=18$ & $>18<=21$ & $>21<=24$ & $>24$ \\
\hline ELILLA & 2.567 & 509 & 384 & 252 & 222 & 120 & 127 & 80 & 106 & 767 \\
\hline 80 & $100 \%$ & $19.83 \%$ & $4.96 \%$ & 9.8240 & 0.0 & 4.6794 & 590 & 3.129 & 4.1390 & $29.88 \%$ \\
\hline ESPAÑA & 895.475 & 281.304 & 135.669 & 86.093 & 64.990 & 39.511 & 36.972 & 30.672 & 25.656 & 194.608 \\
\hline an & 10095 & 31.4190 & $15.15 \%$ & 9.6180 & 7.2690 & 4.4196 & $4.13 \%$ & 3.4390 & $2.87 \%$ & 21.7396 \\
\hline
\end{tabular}

Fuente: Elaboración propia sobre datos del INEM cornespondientes a Junio de 2001 (inwwinem.es)

Por sectores, la agricultura y la industria presentan índices muy bajos de desempleo, por ser sectores de muy escasa presencia en la ciudad. El sector servicios y el colectivo de personas sin empleo anterior representan el mayor porcentaje de desempleados en la ciudad. Por géneros, el desempleo femenino representa más del 70\% del total (cuadros 14 y 15 ).

Cuadro 14: Distribución del desempleo par sectores y género en Melilla

\begin{tabular}{|c|c|c|c|c|}
\hline & & Total edad & Menores de 25 años & Mayores de 25 años \\
\hline & Total & 3.384 & 795 & $2.5 B 9$ \\
\hline \multirow[t]{3}{*}{ Total sectores } & Hombres & 977 & 235 & 742 \\
\hline & Mujeres & 2.407 & 560 & 1.847 \\
\hline & Total & 25 & 2 & 23 \\
\hline \multirow[t]{3}{*}{ Agricultura } & Hombres & 12 & 1 & 11 \\
\hline & Mujeres & 13 & 1 & 12 \\
\hline & Total & 80 & 11 & 69 \\
\hline \multirow[t]{3}{*}{ Industria } & Hombres & 37 & 6 & 31 \\
\hline & Mujeres & 43 & 5 & 38 \\
\hline & Total & 361 & 40 & 321 \\
\hline \multirow[t]{3}{*}{ Construcción } & Hombres & 261 & 33 & 228 \\
\hline & Mujeres & 100 & 7 & 93 \\
\hline & Total & 1.510 & 249 & 1.261 \\
\hline \multirow[t]{3}{*}{ Senvicios } & Hombres & 447 & 79 & 368 \\
\hline & Mujeres & 1.063 & 170 & 893 \\
\hline & Total & 1.408 & 493 & 915 \\
\hline \multirow[t]{2}{*}{ Sin empleo anterior } & Hombres & 220 & 116 & 104 \\
\hline & Mujeres & 1.188 & 377 & 811 \\
\hline
\end{tabular}

Fuente: Datos del INEM correspandentes a Julio de 2001 (muwinemes) 
Cuadro 15: Distribución del desempleo por sectores en Melilla y España

\begin{tabular}{|c|c|c|c|c|c|c|}
\hline & TOTAL & AGRICULTURA & INDUSTRIA & CONSTRUCCION & SERVICIOS & $\begin{array}{l}\text { SIN EMPLEO } \\
\text { ANTERIOR }\end{array}$ \\
\hline MELILLA & 3.743 & 34 & 89 & 491 & 1.632 & 1.497 \\
\hline 96 & 100 & 0.9196 & 2.3896 & 13.1290 & $43.60 \%$ & 39.9996 \\
\hline ESPAÑ̃A & 1.460 .586 & 41.304 & 233.931 & 144.335 & 803.754 & 237.262 \\
\hline 96 & 100 & $2.83 \%$ & $16.02 \%$ & 9.8840 & 55.0396 & 16.2490 \\
\hline
\end{tabular}

Fuente: Elaboración propia sobre datos del INEM correspondientes a Junio de 2001 (www.inem.es)

Según el nivel de estudios, las personas con estudios primarios o EGB son las que más dificultades tienen a la hora de encontrar empleo. A pesar de que un porcentaje alto de la población activa no tiene estudios, el número de parados correspondiente a este grupo sólo es el $0,83 \%$ de la población.

Cuadro 16: Distribución del desempleo por nivel de estudios en Melilla y España

\begin{tabular}{|c|c|c|c|c|c|c|c|c|c|}
\hline & TOTAL & SIN EST. & EST. PRIM. & CERT. ESC. & EG.B & BUP & FP & TIT. MEDIO & $\prod_{\text {SUPER }}^{\text {mT. }}$ \\
\hline MELILLA & 3.743 & 31 & 815 & 1.135 & 953 & 351 & 192 & 189 & 77 \\
\hline PORCENTAUE & 10090 & 0.8386 & $21.77 \%$ & $30.32 \%$ & 25.4606 & $9.38 \%$ & $5.130 \%$ & $5.05 \%$ & 2.0696 \\
\hline ESPAÑA & 1.460 .586 & 5.490 & 83.043 & 428.440 & 504.583 & 161.858 & 117.737 & 70.989 & 88.446 \\
\hline PORCENTAJE & 100.00 & 0.38 & 5.69 & 29.33 & 34.55 & 11.08 & 8.06 & 4.86 & 6.06 \\
\hline
\end{tabular}

Fuente: Elaboración propla scbre datos del INEM cornespondientes a Junio de 2001 (wwm inem.es)

En cuanto a los ingresos medios de las personas que trabajan, son de alrededor de 165.000 pesetas. pero con una distribución muy irregular, tanto geográficamente como según los grupos sociales, como se aprecia en los cuadros 17 y 18 .

Cuadro 17: Ingresos de trabajadores según distritos en miles de pesetas)

\begin{tabular}{|c|c|c|c|c|c|c|c|c|}
\hline & D. 1 & D. 2 & D. 3 & D. 4 & D. 5 & D. 6 & D. 7 & D. 8 \\
\hline$>=50$ & $09 \%$ & 4.896 & 23,100 & $14.8 \%$ & $4,40 \%$ & $09 \%$ & 3,496 & 0.980 \\
\hline $51-100$ & 026 & $14,3 \%$ & $30,8 \%$ & 22.296 & $8.9 \%$ & $22,2 \%$ & $6,9 \%$ & 10,80 \\
\hline $101-150$ & $9.1 \%$ & $19.0 \%$ & $7.79 \%$ & 48.196 & $28.9 \%$ & 11.196 & $27,6 \%$ & $18,0 \%$ \\
\hline $151-200$ & $36.4 \%$ & 4,896 & $15,4 \%$ & $7.40 \%$ & $31.1 \%$ & $33,3 \%$ & $34.5 \%$ & $27,9 \%$ \\
\hline $201-250$ & 18.296 & $9.5 \%$ & 7,780 & $3,7 \%$ & 13,390 & 11,190 & $10.3 \%$ & 9.990 \\
\hline $251-300$ & 096 & 28,695 & $0 \%$ & $0 \%$ & $4.4 \%$ & 11.190 & 6.996 & 12,690 \\
\hline $301-400$ & 27,396 & $4,8 \%$ & $0 \%$ & $3,7 \%$ & $0 \%$ & $0 \%$ & $3,4 \%$ & 7,200 \\
\hline $401-500$ & $0 \%$ & $9.5 \%$ & 7.790 & 090 & $2.2 \%$ & 090 & 096 & $4.5 \%$ \\
\hline $501-750$ & $9.1 \%$ & $0 \%$ & $09 \%$ & 090 & 025 & 090 & 0 ס & .996 \\
\hline $751-1000$ & 096 & $00 \%$ & 094 & 086 & $0 \%$ & $0 \%$ & $0 \%$ & .990 \\
\hline NS / NC & 095 & 4.890 & $7,7 \%$ & 090 & 6.790 & 11.190 & 6.996 & 6.390 \\
\hline Total & 100,0\% & $100,0 \%$ & $100,0 \%$ & $100,0 \%$ & $100,0 \%$ & 100,090 & $100,0 \%$ & $100,0 \%$ \\
\hline
\end{tabular}




\begin{tabular}{|c|c|}
\hline Media & 164.100 \\
\hline Hombre & 182.300 \\
\hline Mujer & 123.000 \\
\hline Hispano & 202.400 \\
\hline Hebreo & 208.300 \\
\hline Bereber & 112.200 \\
\hline Mixta & 164.300 \\
\hline \multicolumn{2}{|l|}{ Lugar de origen } \\
\hline El mismo donde reside & 163.500 \\
\hline Otro de España & 227.000 \\
\hline Extranjero & 112.500 \\
\hline \multicolumn{2}{|l|}{ Edad } \\
\hline De 16 a 19 años & 75.000 \\
\hline De 20 a 24 años & 107.000 \\
\hline De 25 a 29 años & 132.600 \\
\hline De 30 a 39 años & 186.000 \\
\hline De 40 a 49 años & 209.900 \\
\hline De 50 a 59 años & 167.500 \\
\hline Más de 60 años & 111.300 \\
\hline \multicolumn{2}{|l|}{ Distrito } \\
\hline Distrito 1 & 268.200 \\
\hline Distrito 2 & 210.700 \\
\hline Distrito 3 & 133.900 \\
\hline Distrito 4 & 93.600 \\
\hline Distrito 5 & 127.800 \\
\hline Distrito 6 & 137.500 \\
\hline Distrito 7 & 157.500 \\
\hline Distrito 8 & 193.800 \\
\hline
\end{tabular}

Como se puede ver en las tablas, los ingresos son significativamente mayores en el caso de los hombres que en el de las mujeres. Por culturas, los ingresos medios de las personas de origen hispano casi duplican a los de las personas de origen bereber. Los españoles residentes en Melilla pero naturales de otras provincias son las que tienen una media de ingresos más alta. Por edades, los menores de veinte años tienen los ingresos medios más bajos, y estos van subiendo, comenzando un descenso a partir de los cincuenta años. Por distritos, los de ingresos medios más bajos son los tres, cuatro y cinco, encontrando de nuevo que coinciden con los de población mayoritariamente bereber.

La economía de Melilla está condicionada por su pequeña extensión, su separación del territorio peninsular y su situación en el territorio marroquí.

El pequeño tamaño condiciona su carencia casi total de materias primas y recursos energéticos, imprescindibles para la actividad industrial. La actividad agrícola es casi inexistente y la pesquera, antes importante, ha ido desapareciendo ante la presión de Marruecos. Con la desaparición de la pesca ha ido desapareciendo la poca industria que existía, vinculada a este sector. 
Por tanto, el sector primario y el secundario (excepto la construcción) tienen muy poco peso en la actividad económica de Melilla. El sector que predomina es el terciario. Un $85 \%$ de los trabajadores melillenses pertenecen a este sector.

Melilla tiene un régimen económico y fiscal especial Melilla puerto franco -con entrada y salida libre de mercancías en sus territorios- y su estatuto especial dentro de la Unión Europea, así como las bonificaciones fiscales en impuestos directos (el $50 \%$ de deducción en el IRPF sobre rentas obtenidas en Melilla y en el impuesto de sociedades con respecto a rendimientos e incrementos) e indirectos (está excluida del ámbito de aplicación del IVA y de los impuestos especiales sobre tabaco, bebidas alcohólicas e hidrocarburos].

Los impuestos municipales hacen que los ingresos de las arcas del Ayuntamiento de Melilla sean muy altos respecto a los de otras ciudades de España. El principal de estos impuestos es el arbitrio sobre la producción e importación (IPSI). Además, el Ayuntamiento de Melilla recauda los impuestos sobre bienes inmuebles, IAE, vehículos, construcciones, incrementos de valor de los terrenos, hidrocarburos y tabaco.

A pesar de los beneficios fiscales, no se han atraído hacia Melilla grandes inversiones. En la raíz de este problema está, probablemente, la carencia de espacio y de materias y recursos energéticos para la implantación de cualquier industria.

Como decíamos, el sector terciario es el que predomina en la ciudad. Destaca el gran número de empleados en el sector público (cerca del $45 \%$ de las personas empleadas en Melilla lo están en las administraciones local o central), que se incrementa con la fuerte presencia militar en la ciudad y ha crecido con la profesionalidad de la tropa. El comercio es el otro sector hipertrofiado en Melilla, agrupando a, aproximadamente, a un $20 \%$ de los trabajadores (4) y aportando cerca del $90 \%$ del valor añadido bruto provincial (más de 80.000 millones de pesetas] (5).

El comercio "de bazar" con destino a la Península ha decaído a partir de la entrada de España en la CEE y de la presencia de grandes superficies y cadenas de ventas multinacionales. En estos momentos es muy activo el comercio con Marruecos. Productos de bienestar análogos a los que hace dos décadas eran demandados desde la Península, ahora son demandados desde Marruecos (alimentación, bebidas, tecnología), para su consumo en el país o para su redistribución a terceros países. Los altos aranceles de Marruecos hacen que las mercancías importadas desde Melilla resulten más baratas que las que entran directamente en Marruecos. La comunidad hindú y la hebrea se han especializado en la importación directa a los países productores, especialmente a los asiáti$\cos$, mientras que la redistribución hacia Marruecos la realizan, principalmente, miembros de la comunidad musulmana. Los comerciantes de la comunidad hispana se dedican principalmente a productos importados desde la Península o de países de la CEE (6).

4. Estimaciones según datos de la EPA y aitas en la Seguridad Social.

5. Según datos de 1993. (Cf. Melilla en Cifras (1999). p. 148). Estas cantidades se refieren sólo al comencio y empleo declarado en el sector. Hay que considerar que aún hay que añadirles el volumen económico de las operaciones comerciales "irregulares". 6. Datos obtenidos del material del estudio sobre economf́a sumergida en Melilla (análisis DAFO de comerciantes pertenecientes a las tres comunidades). actualmente en elaboración por el Pacto Territorial por el Empleo en Melilla. 
Según las zonas de la ciudad se diferencia el tipo de comercio. En los distritos uno, cuatro y cinco la actividad comercial es prácticamente inexistente (comercios de proximidad). En los distritos céntricos (dos y seis) y en el ocho (en la zona del Paseo Marítimo y Barrio Industrial) se encuentran principalmente comercios minoristas destinados, principalmente al abastecimiento de la población de Melilla, aunque también se realizan numerosas ventas a ciudadanos marroquíes que acuden buscando productos de calidad. Ropa, calzado y demás bienes de consumo, muebles, electrodomésticos y automóviles se concentran en estas zonas principalmente. En el distrito dos también se encuentran algunos bazares, que en otro tiempo fueron los elementos más característicos del comercio melillense. El distrito tres concentra las veritas minoristas o de cantidades no muy grandes, destinadas principalmente a ciudadanos marroquíes, en pequeños bazares. Este distrito era hasta hace una década el que concentraba las ventas a Marruecos, pero ahora esta actividad se ha desplazado a los distritos siete (polígono del SEPES) y ocho (en la zona de naves próxima a la frontera de Beni-Enzar).

El "comercio irregular", o contrabando, es una actividad económica, no por ilegal menos importante en Melilla. Surge de la diferencia entre la situación económica entre los dos países. El estatuto de puerto franco de Melilla, unida a la política económica de Marruecos, que grava con fuertes impuestos la importación, facilita la existencia del contrabando. A pesar de las numerosas campañas organizadas en Marruecos con el objeto de combatir el contrabando, este no ha disminuido, ya que es la principal fuente de ingresos de numerosas familias de las comarcas cercanas a Melilla. Los productos objetos de este tráfico son de lo más variados, como ya hemos señalado: productos alimenticios de primera necesidad (aceite, azúcar) o de consumo; bebidas alcohólicas (que en Marruecos están gravadas con fuertes impuestos, además de que su adquisición y consumo están "mal vistos" por el Islam); productos de tecnología (desde pilas alcalinas a teléfonos móviles, antenas parabólicas o componentes de hardware); productos de perfumería y cosmética; gasolina (en automóviles adaptados para ese fin en el que todo el maletero se ha convertido en depósito de líquido), sanitarios, muebles, etc. El volumen de negocio generado por el contrabando es muy difícil de calcular, dado que no existe registro alguno, pero fuentes del CESID cifraban en 28.000 millones de pesetas el valor de las mercancías sacadas de Melilla mediante este comercio atípico en un periodo de seis meses (GARCÍA FLORES, D. 1999; p. 244).

Paralelamente al contrabando que se genera desde Melilla hacia Marruecos, existe otro que entra de Marruecos a Meilla. Una pequeña parte de este estaría compuesto por productos alimenticios de producción marroquí, especialmente frutas, verduras y pescado, que se adquiere en las localidades vecinas a la frontera de Mariguari, Barrio Chino o Zoco el Had y se venden en Melilla de forma ambulante. Es también corriente que muchos melillenses crucen la frontera para adquirir estos productos, ya que en Marruecos están bastante más baratos. La parte fuerte del contrabando que llega desde Marruecos a Melilla es el de los derivados del Cannabis. El hachis, procedente 
de la zona del Rif, y que desde Melilla se distribuye hacia otros destinos por medio de las lanchas rápidas que hacen de lanzaderas para transportarlo a buques mayores en alta mar, o de personas que lo transportan personalmente, mueve un importante volumen de dinero.

Esto nos lleva a otro rasgo distintivo de la economía de Melilla: el blanqueo de dinero. Los capitales generados por el tráfico de drogas ilegales y parte del capital de personas que se han enriquecido con el contrabando, necesitan ser legalizados, sobre todo ante la inminencia de la implantación de la moneda única europea. La creación de sociedades y empresas fantasma, de establecimientos comerciales sin aparente movimiento, el espectacular incremento de la construcción y de la adquisición de inmuebles y el cambio de divisas de numerosos países, desmesurado para una ciudad con las características de Melilla están directamente relacionados con las operaciones de blanqueo de dinero, creando en Melilla un movimiento económico durante los últimos años que ha originado una fuerte inflación (sobre todo en el precio de las viviendas y locales comerciales) y que, según apuntan todas las previsiones, no se podrá sostener a partir del 2002.

Actualmente el comercio de Melilla se siente amenazado por la bajada de aranceles de Marruecos, prevista para el año 2006 y por el anuncio, realizado en el mes de agosto de este año, 2001, de convertir en puerto franco zonas cercanas a Melilla y Ceuta. Esto pone a la economía Melillense ante el desafío de buscar espacios que permitan competir en esas circunstancias.

Como último rasgo de la economía de Melilla, señalamos que, por haber sido considerada objetivo prioritario para recibir las ayudas de los fondos estructurales de desarrollo, y fondos de cohesión de la Unión Europea. Estos fondos cofinancian programas de intervención para reparar deficiencias existentes en la estructura económica y social de la ciudad. El montante total de la financiación recibida de la Unión Europea a través de los Fondos de Desarrollo y de Cohesión ascendió a 11.500 (7) millones de pesetas, empleados principalmente en obras de infraestructura y en el apoyo a empresas; en el periodo 1994-1999 la inversión de la UE ha sido de 6.229 (8) millones de pesetas. Para la ejecución de estas medidas se ha creado una empresa pública, Proyecto Melilla S.A., encargada de la ejecución de las medidas, junto a las administraciones local y central. 


\section{Algunas necesidades que plantea la situación de Melilla}

\section{Educación y formación}

- Educación infantil y juvenil: medidas y alternativas que compensen las diferencias lingüísticas y culturales.

- Educación de Adultos: Reducir la alta tasa de analfabetismo.

\section{Economía y Empleo}

- Formación ocupacional: Adecuación a la realidad del mercado de trabajo (demandas de los empresarios. Nuevos Yacimientos de Empleo, circunstancias de los demandantes de empleo...).

- Búsqueda de alternativas económicas viables y sostenibles para la ciudad y fomento de las mismas.

- Fomento del autoempleo, apoyo a emprendedores.

- Intermediación eficaz en el mercado de trabajo.

Intervención sobre los espacios urbanos

- Regularización y legalización.

- Mejora de las infraestructuras (limpieza, seguridad, servicios, espacios de ocio...)

\section{Tejido social}

- Participación ciudadana

- Foros de intercambio, diálogo y cooperación

- Articulación de mecanismos que hagan posible la Democracia Participativa y el control de los representantes políticos por los ciudadanos. 


\section{Prevención integral de la exclusión social}

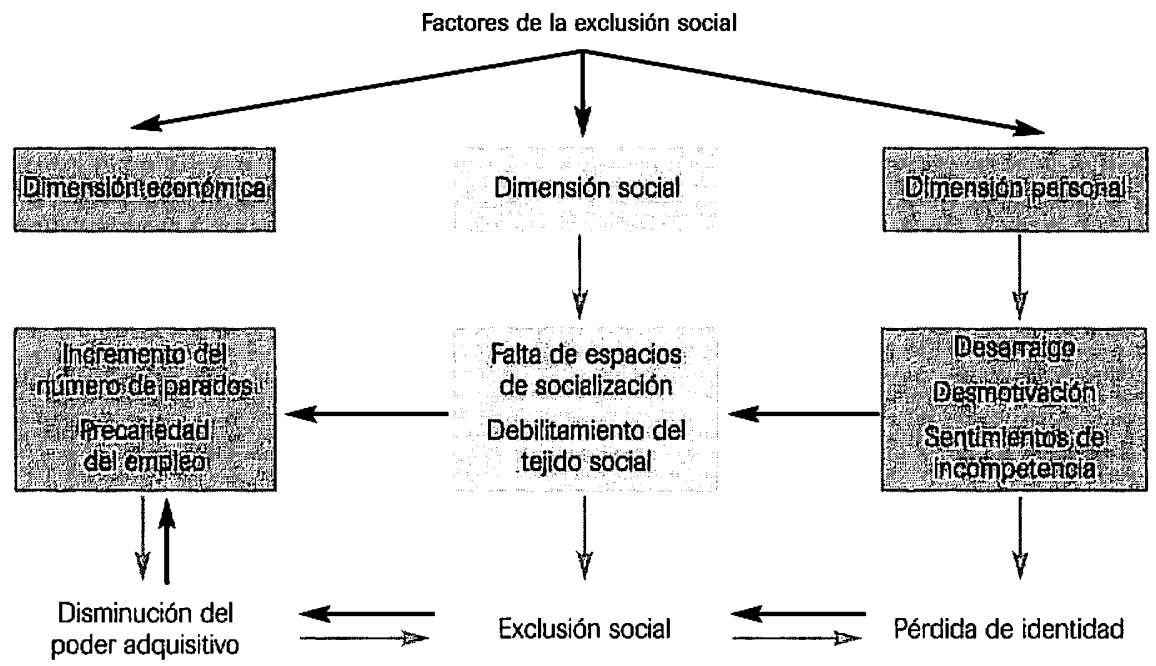




\section{Dinámica institucional de mantenimiento de la exclusión social}

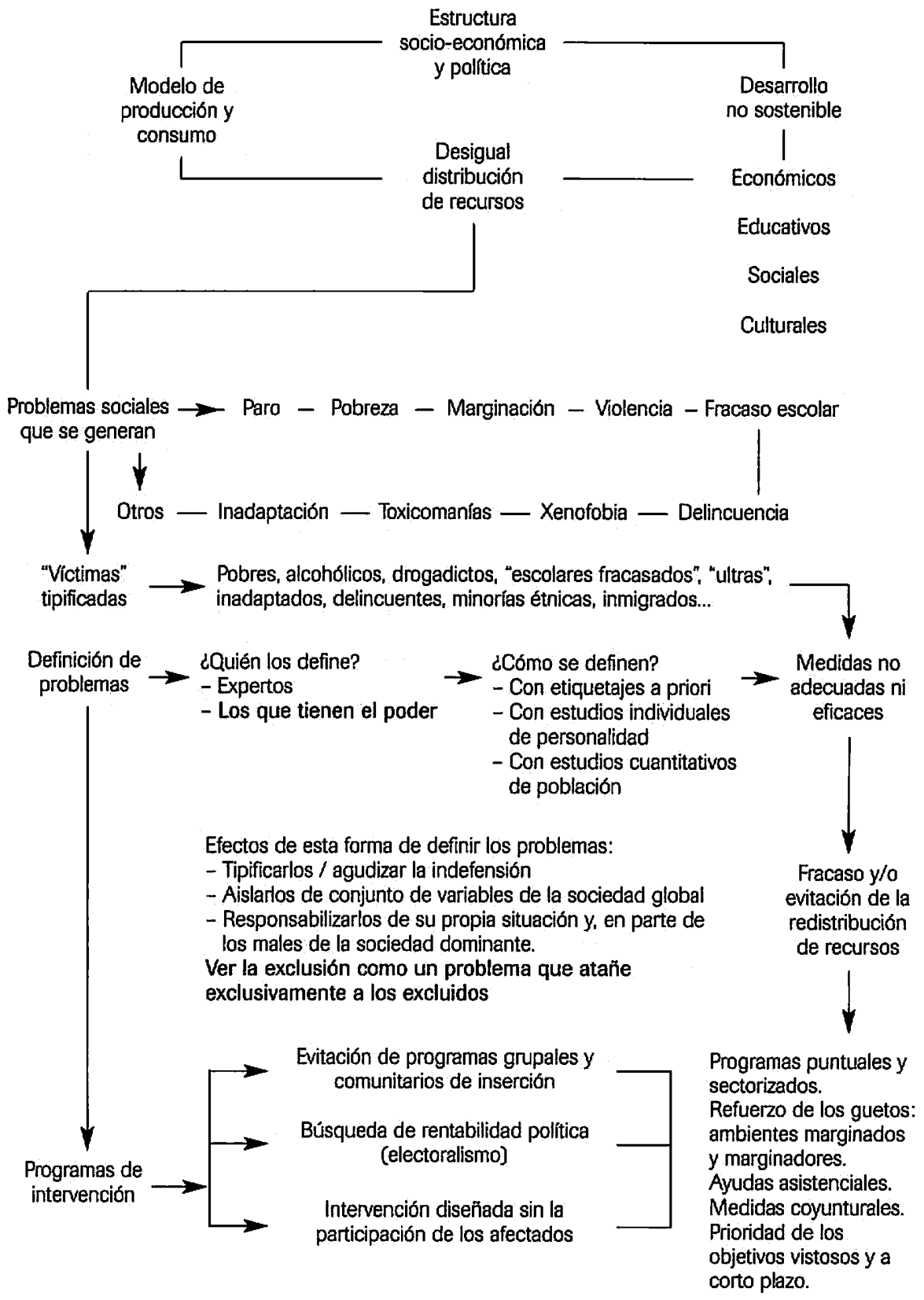


Necesidad de activar medios y recursos:

Cambiar el modelo de intervención "Vertical Descendente" por un modelo "reticular y bidireccional"; que:

- facilite el intercambio entre los diferentes elementos que forman la red social

- utilice prioritariamente los recursos que se encuentran en la propia comunidad

- convierta los recursos institucionales en auténticos recursos comunitarios

- retroalimente a los representantes institucionales

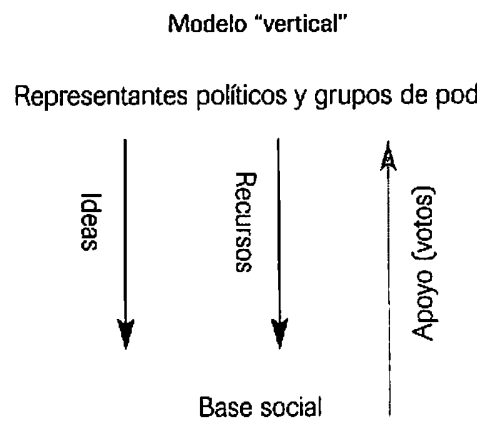

Modelo "reticular"

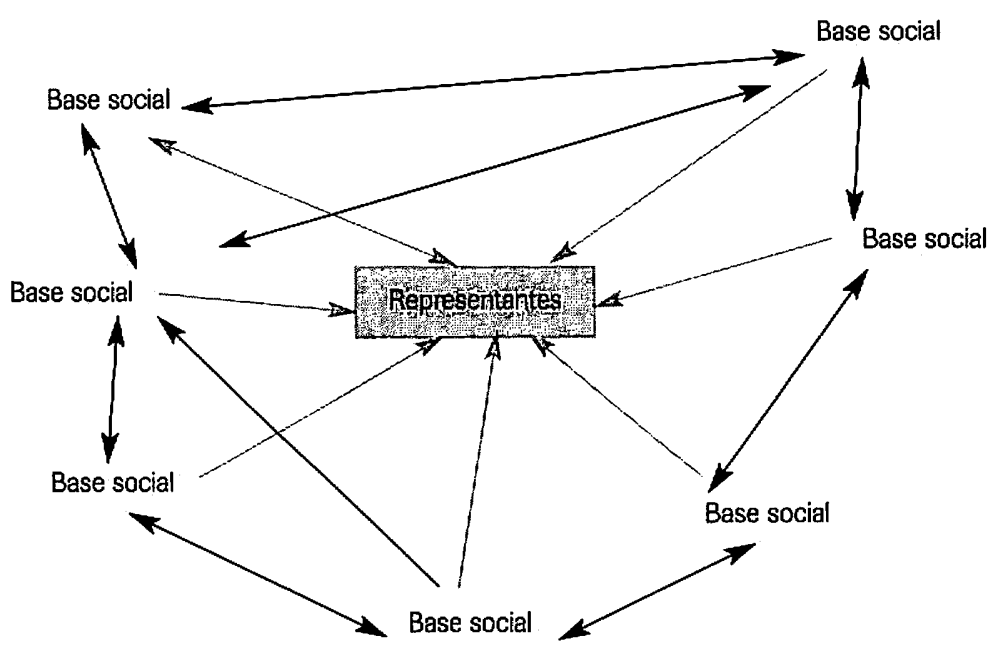




\section{La educación como subsistema social}

Función de reproducción social de la educación: adaptar al sujeto a los procesos productivos-reproductivos del orden social vigente.

Por lo tanto, la educación debe estar en congruencia con los fines últimos

-de la especie humana (sobrevivir como especie biológica).

- de la cultura (salvaguardar el conjunto de interpretaciones que se dan sobre el acontecer y lo que en él pasa para que el hombre tenga un sentido en la vida)

- y del mismo grupo social (para conservar territorio, bienes materiales y formas de producir satisfactores materiales $y / 0$ inmateriales).

El aula como espacio social donde se realiza una gran cantidad de prácticas en las que se materializan y toman forma los fines de la institución, los planes de estudio, la concepción del conocimiento y la organización misma del trabajo.

La educación reproducirá el sistema social en el que se basa.Necesidad de optimizar el proceso de enseñanza-aprendizaje pero no a partir exclusivamente de los procesos didácticos, sino desde un punto de vista sistémico para lo cual será necesario recurrir a los principios de algunas teorías sociales, teorías comunicativas, teorías educativas y de aprendizaje.

\section{Teorías de apoyo para una educación integradora}

- Teoría General de Sistemas: brinda elementos de carácter metodológico para analizar la Educación como un sistema a partir de la selección, distinción y relación de sus elementos. Lo que le permite concebirla como un (sub)sistema autónomo y abierto a las interacciones de otros sistemas.

- Teoría de la Mediación Social: permite interpretar y sistematizar la diversidad de elementos que se constituyen en el proceso educativo pues brinda elementos para concebir la Comunicación Educativa y a la Educación como actividades mediadoras y a las instituciones educativas y a los medios de comunicación como instancias mediadoras.

- La Teoría Social de la Comunicación: permite identificar a los elementos comunicativos que intervienen en el proceso educativo, lo cual explica cómo se producen y cambian las afectaciones entre comunicación y sociedad.

\section{Estrategias para una educación integradora}

- Aprendizaje Significativo: propiciar aprendizajes, no mecánicos ni por repetición sino significativos.

- Aprendizaje Grupal: promover una forma diferente de vinculación entre el actor coordinador y los actores miembros del grupo y los contenidos y el grupo y la tarea. 
- Comunicación Participativa: fomentar la interacción de los actores en aula a partir de la participación y el diálogo para que puedan expresar sus necesidades e intereses para apropiarse no de un conocimiento acumulado sino de un saber reflexivo.

- Educación Integral: lograr el desarrollo armónico de las áreas afectiva, intelectual y psicomotora de los actores miembros del grupo.

\section{Presupuestos para la intervención}

- Un concepto de la persona: ser en relación, sistema complejo en sí mismo que encuentra su propia identidad en la pertenencia dinámica a sistemas relacionales (redes).

- Un replanteamiento de las relaciones entre subredes sociales, poniendo medios para ofrecer alternativas a la dinámica inclusión-exclusión (con sus elementos de competitividad entre individuos y grupos, de rechazo a lo diferente, de sistemas cerrados y opuestos de valores...).

- Un convencimiento de que este tipo de relación basada en la identificación con el propio grupo y el rechazo o cerrazón hacia los otros, además de no favorecer el bien común, tampoco favorece a la larga el interés de ningún grupo, ya que genera tensiones sociales que frenan lo que podría ser un desarrollo armónico y sostenible.

- Una alternativa basada en relaciones de cooperación-apertura; en la localización de los intereses comunes y en los medios que, desde los recursos y posibilidades de cada colectivo se pueden ofrecer para alcanzar cotas mayores de convivencia y bienestar para todos.

Desde esta perspectiva, se plantea la formación de agentes de mediación social, que desarrollarían la tarea de enlazar las distintas redes sociales (ya sean formales o informales), equilibrando las desigualdades que impiden que la igualdad de oportunidades que en teoría existe en un estado de derecho sea real, y abriendo cauces de comunicación, consenso y acción común en la solución de conflictos que, de una forma u otra, repercuten en el conjunto de la gran red social.

\section{La IAP aplicada a la formación}

Los principios de la Investigación-Acción Participativa se adaptarían a la tarea formativa bajo los siguientes presupuestos metodológicos:

- Valora el conocimiento que los propios ciudadanos tienen de los procesos en que se ven inmersos y la necesidad de explicitar, sistematizar y aplicar ese conocimiento práctico y "popular" para lograr las transformaciones necesarias para mejorar las condiciones de vida de las personas.

- Está orientado a la toma de conciencia de los propios recursos, potencialidades, y necesidades de la comunidad; a la "toma de poder" de las bases sociales. Y también 
a detectar las dificultades inherentes al sistema de relaciones dentro de los grupos o "sub-redes" sociales y entre diferentes niveles de la gran Red.

- Es eminentemente práctico, aunque procure dotar de una base teórica y reflexiva a la acción. La finalidad de la teoría no es lograr un "saber por saber", sino contextualizar el conocimiento con vistas a mejorar la praxis.

- Es intencional y crítico. No pretende ser un conocimiento neutral de la realidad, ya que está orientado a su transformación desde el punto de vista de las bases, y para ello es preciso que cuestione las "versiones oficiales; que tenga un talante subversivo (entendiendo la sub-versión como búsqueda de la "versión" de la realidad que subyace a las interpretaciones que de ella hacen quienes ostentan las posiciones de poder y de creación y difusión de la información.

- Es "poliédrico". A pesar de su intencionalidad, no se queda en una perspectiva única, sino que busca una visión lo más diversificada posible, contemplando y valorando la realidad desde diferentes ángulos, siempre conscientes de su complejidad y de que desde un análisis que contemple un único punto de vista sólo se pueden encontrar soluciones que respondan a intereses particulares.

- Es dialéctico, consciente de que la realidad es dinámica y se produce una continua interacción de diferentes fuerzas y movimientos. Cada acción presenta nuevas posibilidades y cada descubrimiento nuevas preguntas.

- Es colectivo, basándose en el aprendizaje en grupo para la acción en grupo.

- Es expansivo, ya que su finalidad es formarse para formar, para adaptar las actitudes, conocimientos y técnicas empleadas a los propios grupos, asociaciones o comunidades.

- Es público, orientado a la publicación y difusión del conocimiento adquirido (o producido] de forma que se convierta en información que cuestione, motive e impulse la participación, la mediación y la negociación entre diferentes niveles de la red social. 